Case Report

\title{
Esophagojejunal Anastomosis Fistula, Distal Esophageal Stenosis, and Metalic Stent Migration after Total Gastrectomy
}

\author{
Nadim Al Hajjar, ${ }^{1,2}$ Calin Popa, ${ }^{1,3}$ Tareg Al-Momani, ${ }^{3,4}$ Simona Margarit, ${ }^{5,6}$ \\ Florin Graur, ${ }^{1,2}$ and Marcel Tantau ${ }^{7,8}$ \\ ${ }^{1}$ Department of Surgery, Regional Institute of Gastroenterology and Hepatology "Prof. Dr. Octavian Fodor", Croitorilor Street, \\ No. 19-21, 400162 Cluj-Napoca, Romania \\ ${ }^{2} 3$ rd Surgical Clinic, Iuliu Hatieganu University of Medicine and Pharmacy, Croitorilor Street, No. 19-21, 400162 Cluj-Napoca, Romania \\ ${ }^{3}$ Training and Research Center "Prof. Dr. Sergiu Duca", Petre Ispirescu Street, No. 1, 400090 Cluj-Napoca, Romania \\ ${ }^{4}$ Department of Oncological Surgery, The Oncology Institute "Prof. Dr. Ion Chiricuţă" Republicii Street, No. 34-36, \\ 400015 Cluj-Napoca, Romania \\ ${ }^{5}$ Department of Intensive Care Unit, Regional Institute of Gastroenterology and Hepatology "Prof. Dr. Octavian Fodor", \\ Croitorilor Street, No. 19-21, 400162 Cluj-Napoca, Romania \\ ${ }^{6} 1$ st Anesthesiology and Critical Care Clinic, Iuliu Hatieganu University of Medicine and Pharmacy, Croitorilor Street, No. 19-21, \\ 400162 Cluj-Napoca, Romania \\ ${ }^{7}$ Department of Gastroenterology, Regional Institute of Gastroenterology and Hepatology "Prof. Dr. Octavian Fodor", Croitorilor Street, \\ No. 19-21, 400162 Cluj-Napoca, Romania \\ ${ }^{8} 3$ rd Medical Clinic, Iuliu Hatieganu University of Medicine and Pharmacy, Croitorilor Street, No. 19-21, 400162 Cluj-Napoca, Romania
}

Correspondence should be addressed to Calin Popa; calinp2003@yahoo.com

Received 6 December 2014; Revised 25 March 2015; Accepted 30 March 2015

Academic Editor: Shin-ichi Kosugi

Copyright (C) 2015 Nadim Al Hajjar et al. This is an open access article distributed under the Creative Commons Attribution License, which permits unrestricted use, distribution, and reproduction in any medium, provided the original work is properly cited.

Esophagojejunal anastomosis fistula is the main complication after a total gastrectomy. To avoid a complex procedure on friable inflamed perianastomotic tissues, a coated self-expandable stent is mounted at the site of the anastomotic leak. A complication of stenting procedure is that it might lead to distal esophageal stenosis. However, another frequently encountered complication of stenting is stent migration, which is treated nonsurgically. When the migrated stent creates life threatening complications, surgical removal is indicated. We present a case of a 67-year-old male patient who was treated at our facility for a gastric adenocarcinoma which developed, postoperatively, an esophagojejunostomy fistula, a distal esophageal stenosis, and a metallic coated self-expandable stent migration. To our knowledge, this is the first reported case of an esophagojejunostomy fistula combined with a distal esophageal stenosis as well as with a metallic coated self-expandable stent migration.

\section{Introduction}

With every year passing, the incidence of complications following a total gastrectomy is decreasing; literature review shows it occurs in approximately $7-27 \%$ of cases [1-4]. Esophagojejunal anastomosis fistula is the main complication of this procedure, with a high mortality rate of around $20 \%$, which represents $30-65 \%$ of global postgastrectomy mortality [4-8].
Surgeons tried since the beginning to treat these postoperative leaks and fistulae with drainage and repair, complete parenteral nutrition with no oral intake, and combining these with antibiotics. Nonetheless, this approach had a significant morbidity and mortality rates of up to $60 \%$ $[9,10]$.

Interventional endoscopy comes to the rescue by placing coated self-expandable stents in patients with esophagojejunostomies at the site of the anastomotic leakage. This 


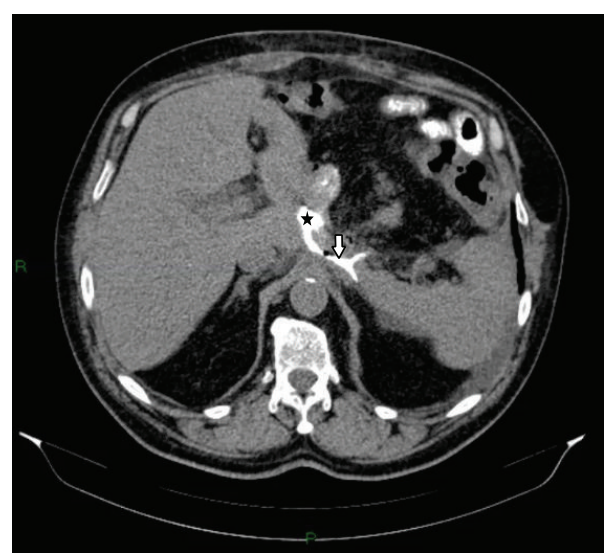

Figure 1: Axial contrast-enhanced abdominal computer tomography (CT): esophageal lumen (star); esophagojejunal anastomotic fistula (arrow).

helps to avoid a complex procedure on friable inflamed perianastomotic tissues $[1,11-13]$.

The most encountered complication of coated selfexpandable stents is stent migration; this according to published literature occurs in up to $28 \%$ of cases [14-16]. Management of this condition usually is nonsurgical, being either repositioned endoscopically, waiting for the stent to be eliminated spontaneously through the rectum, or it might even remain in the body if it does not create complications [17, 18 ]. When the migrated stents create complications, surgical removal is indicated [19].

\section{Case Report}

We present the case of a 67-year-old male patient who was diagnosed with gastric adenocarcinoma intestinal type T2N0M0 (Stage I B), mild microcytic hypochromic anemia, gall bladder lithiasis, essential hypertension grade I, and obesity grade I.

A total gastrectomy with D2 lymphadenectomy with Endto-Side esophagojejunostomy in a transmesocolic Roux-en$\mathrm{Y}$ anastomosis, cholecystectomy, and a feeding jejunostomy were performed.

Postoperative outcome was favorable initially after which his status suddenly worsened, with fever of $38.2^{\circ} \mathrm{C}$, loss of appetite, and leukocytosis with neutrophilia. An oral contrast-enhanced CT was performed which showed an esophagojejunal anastomotic fistula (Figure 1).

A $28 \mathrm{~mm}$ diameter metallic coated self-expandable stent (CSES) was mounted endoscopically on the anastomotic site after which the patient showed a favorable outcome (no reflux complaints) (Figure 2).

48 hours before discharging the patient and 39 days postoperatively, a barium swallow upper GI radiography was performed which showed good esophageal transit with no contrast material leakage at the anastomotic site (Figure 3).

Histopathological examination of the surgical specimen revealed a gastric adenocarcinoma pT3N0MxL0V0R0 (37 lymph nodes were examined). This puts the patient in the IIA stage of the disease.
The metallic CSES was removed one month after placement, after which the patient started having dysphagia episodes three weeks later. Initially the cause of dysphagia was thought to be a stenosis of the esophagojejunal anastomosis; however, it was further investigated where results showed that the stenosis was situated proximal to the anastomosis, which we interpreted as scar tissue after prolonged local pressure on the esophageal wall due to the presence of the proximal stent tulip.

In the following three-month period he received chemotherapy (FU-FOL protocol) and continued having recurrent dysphagia episodes, for which he was being treated repeatedly by interventional endoscopy with balloon and plug dilation (Figure 4).

To avoid recurrent balloon and plug dilatations, a second (22 mm diameter) CSES was placed two months after the removal of the first one on the distal esophageal stenosis, which was removed one month after placement. A third (22 $\mathrm{mm}$ diameter) CSES was placed due to the persisting dysphagia (Figure 5) two months after the removal of the second stent.

One month after the placement of the third stent, the patient presented to the emergency department complaining of diffuse abdominal pain and mixed dysphagia. On physical examination the patient was pale with altered general status and dehydration, and a mass could be palpated in the left paraumbilical region. A fluoroscopy of the abdomen was done, which revealed that the metallic stent has migrated into the jejunum.

Correlating the migration of the stent with the increasing intensity of the abdominal pain, a decision of exploratory laparotomy was made, where exploration revealed that the esophageal stenosis was proximal to the esophagojejunal anastomosis, and a migrated metallic stent located just distally to the anastomotic site of the blind loop of the Rouxen-Y procedure performed initially (Figure 6).

A distal esophagectomy with a new End-to-Side esophagojejunostomy using a $25 \mathrm{~mm}$ circular stapler and an en bloc segmentary enterectomy at the site of the stent (Figure 7), with an End-to-End anastomosis, were performed. 


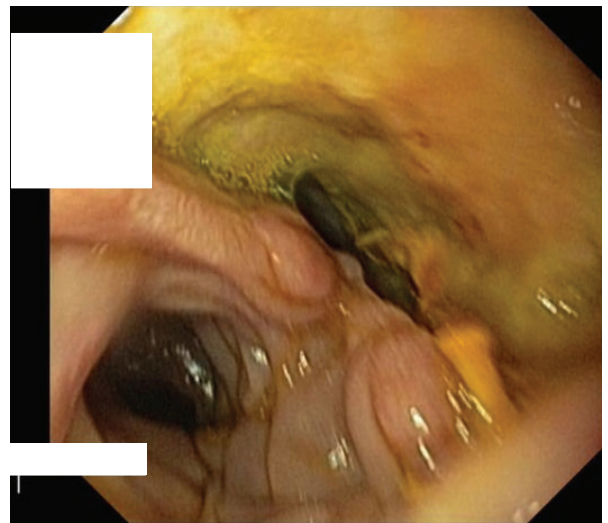

(a)

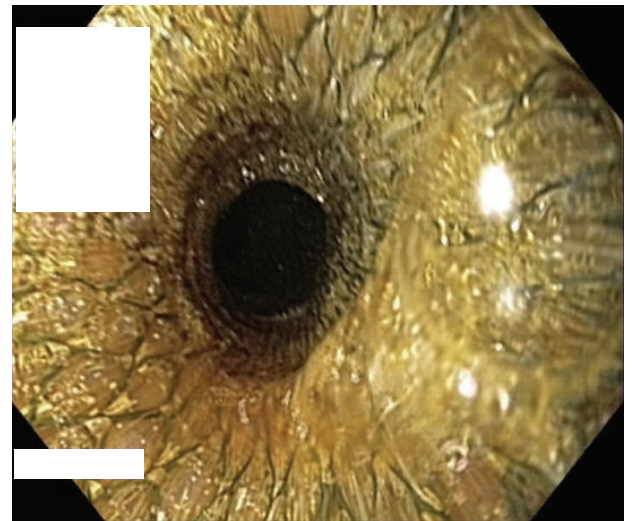

(b)

FIGURE 2: Esophagoscopy: esophagojejunal anastomotic fistula before (a) and after (b) stent placement.

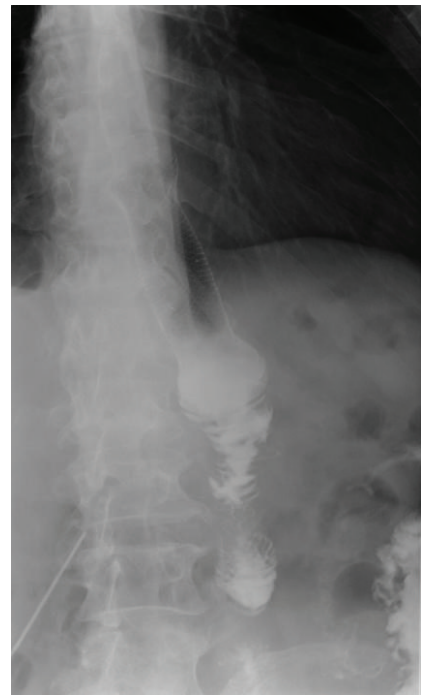

FIGURE 3: Barium swallow: without extraluminal contrast leakage.

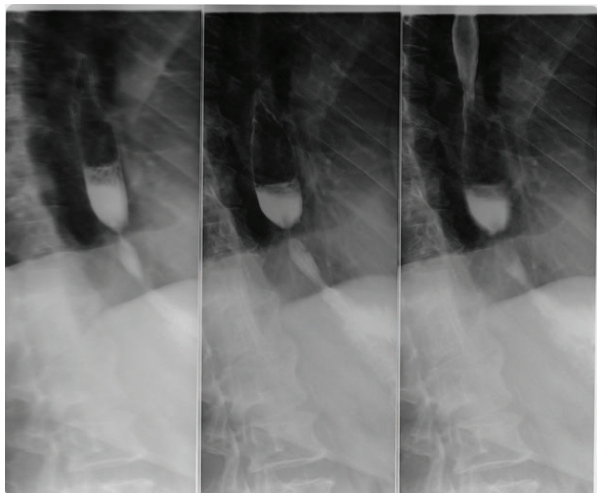

(a)

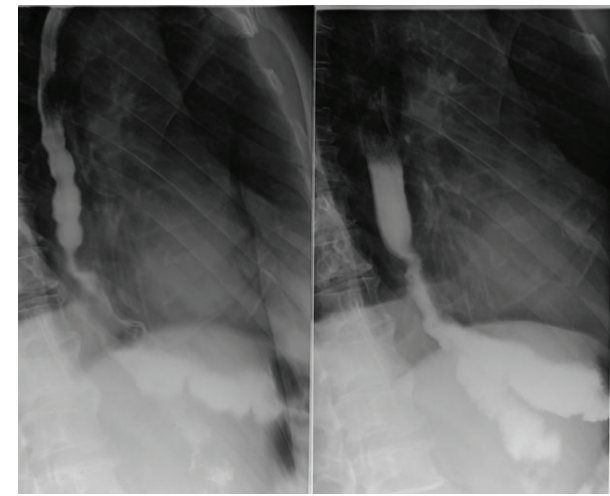

(b)

FIgURE 4: Abdominal X-ray: before (a) and after (b) balloon dilatation. 


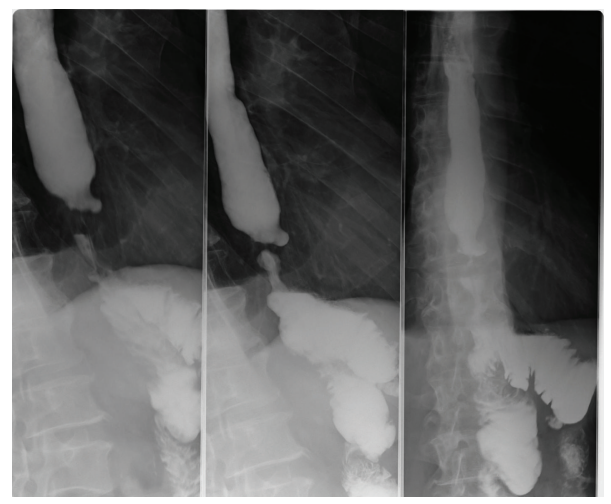

Figure 5: Moderate distal esophageal stenosis before the third stent placement.

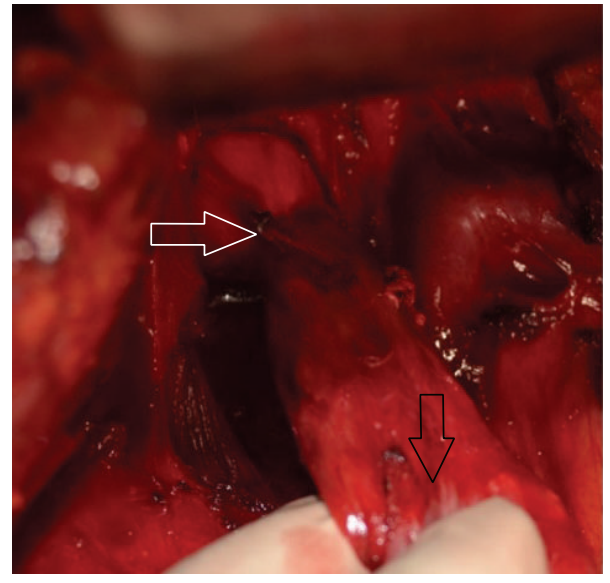

(a)

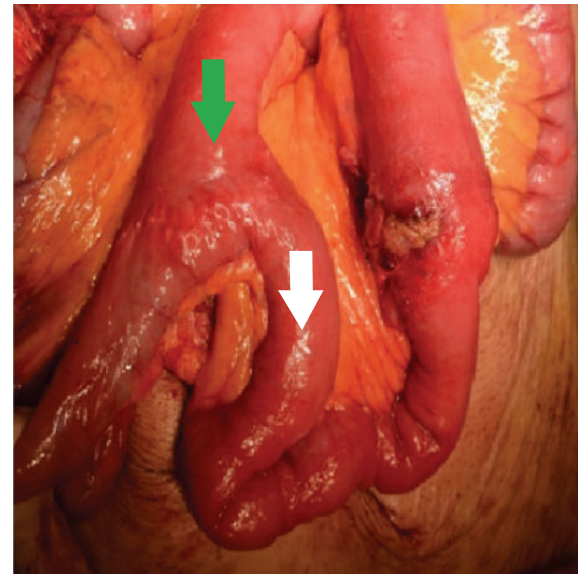

(b)

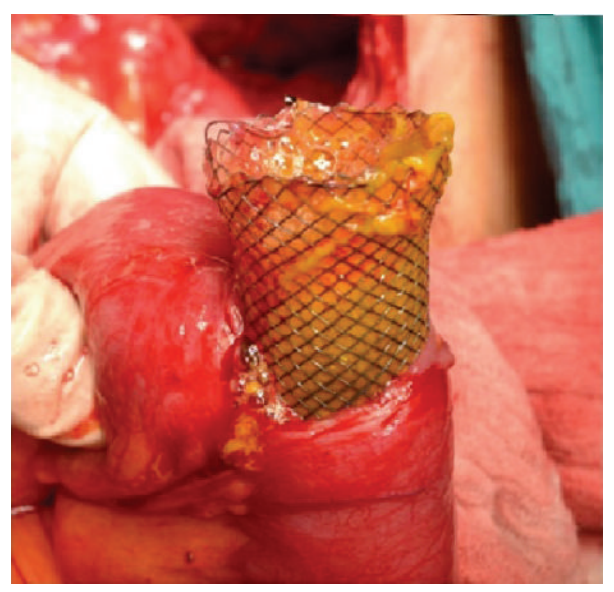

(c)

FIGURE 6: Intraoperative aspects: (a) circumferential distal esophageal stenosis (white arrow), site of esophagojejunal anastomosis (black arrow); (b) migrated stent: direction of migration (white arrow), end-loop proximal small bowel (green arrow); (c) metallic stent into the jejunal lumen.

Postoperative evolution was favorable, with nutrition per os reestablished after CT evaluation 2 weeks after the last operation, and the patient was discharged a week later.
Histopathological examination of the specimens showed that the esophageal stenosis was of benign nature (Figure 8). 


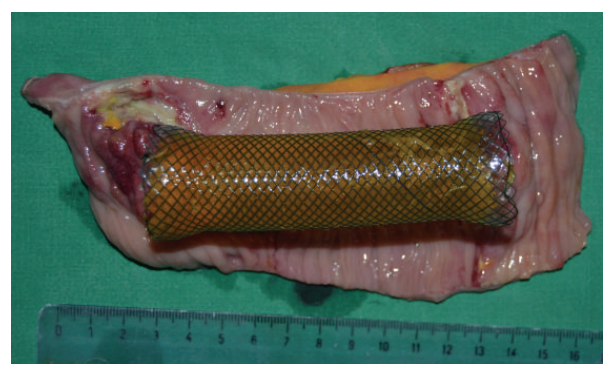

FIGURE 7: Segmentary enterectomy: postresection specimen and metallic stent.

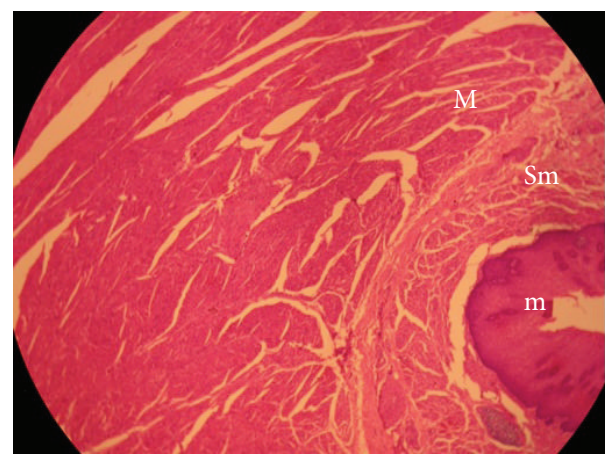

(a)

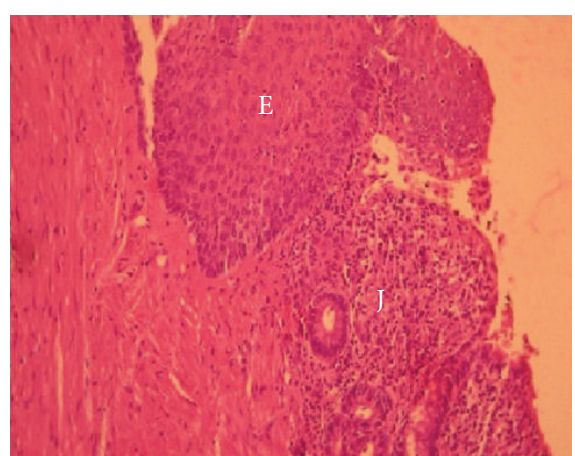

(b)

FIGURE 8: Histopathological findings $(\mathrm{H} \& \mathrm{E} \times 4)$ revealing benign distal esophageal stenosis: (a) cross section above anastomotic site $(\mathrm{m}$ : mucosa, Sm: submucosa, and M: hypertrophic muscularis propria); (b) esojejunal anastomosis (E: esophageal mucosa, J: jejunal mucosa).

The patient was followed up after 6 months after the second intervention, where the esophagojejunal anastomosis was patent with good oral nutrition and gain in weight $(6 \mathrm{Kg})$.

\section{Discussion}

Anastomotic fistula is a complication that is encountered in some patients who underwent gastric surgeries and might lead to poor outcome, poor quality of life, and even life threatening complications. The current management of such cases concentrates on relieving the symptoms, possible complications of the leakage, and providing efficient nutritional support for the patients. This management consists of the drainage of the leaked collections accompanied by long term parenteral nutrition. In more severe cases when the leakage is associated with peritonitis or paralytic ileus, surgical intervention is indicated, despite the possibility of more severe complications due to poor general status of the patient and the high invasiveness of the procedure [20,21].

In cases of minimal leakage, management consists of discontinuing oral intake and feeding through a jejunal feeding tube or parenterally. Literature shows minimally invasive treatments for esophageal anastomotic leaks like fibrin glue application and endoscopic clipping which showed satisfactory results in some cases, but when the anastomotic leak is large, repeated complex interventions are required to seal these fistulas $[22,23]$. Meanwhile endoscopic stenting as a treatment for such fistulas is showing advantages to the patient over immediate surgical reintervention, such as earlier resumption of oral intake, shorter hospitalization, minimal morbidity, better quality of life, and less costs of treatments $[21,24]$.

As any treatment modality, endoscopic stenting has its complications such as hemorrhage, stent migration, strictures, and perforations. Most migrated stents are removed nonsurgically [19]. However, we believe that in such cases surgical intervention is absolutely necessary if life threatening complications (obstruction, perforation) are imminent.

Benign refractory strictures of the esophagus are the ones where dilation to an appropriate diameter fails and strictures that recur after short periods of time as well as the ones that need continuous dilation [25]. These strictures lower the patient's quality of life due to their possible complications like malnutrition, pain, or perforation [26]. Many techniques are available for treating such strictures, out of which is temporary stenting. Stenting is an appealing approach as the placed stent is performing the dilation function for the complete period of placement, and it can be removed when needed. Nonetheless, temporary stenting must be used in carefully chosen patients as it has a high rate of complications. These temporary stents are useful tools in restoring the lumen of the esophagus until the patient's status or treatment plan allows surgical intervention [27].

Reintervention in our patient had a particularity that it had two purposes: to resolve the imminent complication of stent migration and the distal esophageal stenosis.

The multidisciplinary treatment, interventional endoscopy, and surgery were complementary approaches as 
interventional endoscopy managed the surgical complication being an esophagojejunal fistula, and later surgery for managing the endoscopic stenting complication being the distal esophageal stenosis and stent migration.

For this case, endoscopic stenting seemed to be the most appropriate immediate management for the esophagojejunostomy fistula. Operative management for the distal esophageal stenosis would have delayed chemotherapy, whereas stenting enabled chemotherapy administration as early as possible and offered the patient a better quality of life during this phase of treatment as well as avoiding repeated balloon and plug dilatation sessions. Taking into account that the stenosis before the third stent mounting was moderate, it might have contributed to the migration of the stent. When the patient's symptoms indicate an upcoming complication of a migrated stent, we consider the operative removal an essential step for a better prognosis.

\section{Conflict of Interests}

The authors declare that there is no conflict of interests regarding the publication of this paper.

\section{References}

[1] J. Hoeppner, B. Kulemann, G. Seifert et al., "Covered selfexpanding stent treatment for anastomotic leakage: outcomes in esophagogastric and esophagojejunal anastomoses," Surgical Endoscopy and Other Interventional Techniques, vol. 28, no. 5, pp. 1703-1711, 2014.

[2] A. Fernández Villaverde, J. J. Vila, S. Vázquez et al., "Selfexpanding plastic stents for the treatment of post-operative esophago-jejuno anastomosis leak. A case series study," Revista Espanola de Enfermedades Digestivas, vol. 102, no. 12, pp. 704710, 2010.

[3] H. Lang, P. Piso, C. Stukenborg, R. Raab, and J. Jähne, "Management and results of proximal anastomotic leak in a series of 1114 total gastrectomies for gastric carcinoma," European Journal of Surgical Oncology, vol. 26, no. 2, pp. 168-171, 2000.

[4] P. Nowakowski, K. Ziaja, T. Ludyga et al., "Self-expandable metallic stents in the treatment of post-esophagogastrostomy/ post-esophagoenterostomy fistula," Diseases of the Esophagus, vol. 20, no. 4, pp. 358-360, 2007.

[5] H. J. Fahn, L. S. Wang, M.-S. Huang, B.-S. Huang, W.-H. Hsu, and M.-H. Huang, "Leakage of intrathoracic oesophagovisceral anastomoses in adenocarcinoma of the gastric cardia: changes in serial APACHE II scores and their prognostic significance," European Journal of Surgery, vol. 163, no. 5, pp. 345-350, 1997.

[6] T. Aparicio, M. Yacoub, P. Karila-Cohen, and E. René, "Adénocarcinome gastrique: notions fondamentales, diagnostic et traitement," Encyclopédie Médico-Chirurgicale-Chirurgie, vol. 1, no. 1, pp. 47-66, 2004.

[7] A. Sauvanet, L. Berthoux, B. Gayet, J. F. Fléjou, J. Belghiti, and F. Fekete, "Adénocarcinome du cardia: l'étendue de l'éxérèse gastrique et du curage ganglionnaire influence t elle la survie?" Gastroentérologie Clinique et Biologique, vol. 19, pp. 244-251, 1995.

[8] K. Alanezi and J. D. Urschel, "Mortality secondary to esophageal anastomotic leak," Annals of Thoracic and Cardiovascular Surgery, vol. 10, no. 2, pp. 71-75, 2004.
[9] R. C. Karl, R. Schreiber, D. Boulware, S. Baker, and D. Coppola, "Factors affecting morbidity, mortality, and survival in patients undergoing ivor lewis esophagogastrectomy," Annals of Surgery, vol. 231, no. 5, pp. 635-643, 2000.

[10] N. Kumar and C. C. Thompson, "Endoscopic therapy for postoperative leaks and fistulae," Gastrointestinal Endoscopy Clinics of North America, vol. 23, no. 1, pp. 123-136, 2013.

[11] R. Kochar and N. Shah, "Enteral stents: from esophagus to colon," Gastrointestinal Endoscopy, vol. 78, no. 6, pp. 913-918, 2013.

[12] I. I. El Hajj, T. F. Imperiale, D. K. Rex et al., “Treatment of esophageal leaks, fistulae, and perforations with temporary stents: evaluation of efficacy, adverse events, and factors associated with successful outcomes," Gastrointestinal Endoscopy, vol. 79, no. 4, pp. 589-598, 2014.

[13] R. Babor, M. Talbot, and A. Tyndal, "Treatment of upper gastrointestinal leaks with a removable, covered, self-expanding metallic stent," Surgical Laparoscopy, Endoscopy and Percutaneous Techniques, vol. 19, no. 1, pp. 1-4, 2009.

[14] N. Vakil, A. I. Morris, N. Marcon et al., "A prospective, randomized, controlled trial of covered expandable metal stents in the palliation of malignant esophageal obstruction at the gastroesophageal junction," The American Journal of Gastroenterology, vol. 96, pp. 1791-1796, 2001.

[15] N. A. Christie, P. O. Buenaventura, H. C. Fernando et al., "Results of expandable metal stents for malignant esophageal obstruction in 100 patients: short-term and long-term followup," Annals of Thoracic Surgery, vol. 71, no. 6, pp. 1797-1802, 2001.

[16] M. Y. V. Homs, E. W. Steyerberg, E. J. Kuipers et al., "Causes and treatment of recurrent dysphagia after self-expanding metal stent placement for palliation of esophageal carcinoma," Endoscopy, vol. 36, no. 10, pp. 880-886, 2004.

[17] S. R. Puli, I. S. Spofford, and C. C. Thompson, "Use of self-expandable stents in the treatment of bariatric surgery leaks: a systematic review and meta-analysis," Gastrointestinal Endoscopy, vol. 75, no. 2, pp. 287-293, 2012.

[18] Y. S. Oh and M. L. Kochman, "Polyflex esophageal stent migration with elimination per rectum," Gastrointestinal Endoscopy, vol. 66, no. 3, p. 633, 2007.

[19] O. Karatepe, E. Acet, M. Altiok, M. Battal, G. Adas, and S. Karahan, "Esophageal stent migration can lead to intestinal obstruction," North American Journal of Medical Sciences, vol. 1, no. 2, pp. 63-65, 2009.

[20] R. Morgan and A. Adam, "Use of metallic stents and balloons in the esophagus and gastrointestinal tract," Journal of Vascular and Interventional Radiology, vol. 12, no. 3, pp. 283-297, 2001.

[21] Y. P. Cho, D. H. Lee, H. J. Jang et al., "Leakage of jejunal end of Roux limb after total gastrectomy: management with a placement of a covered metallic stent. Case report," Journal of Korean Medical Science, vol. 18, no. 3, pp. 437-440, 2003.

[22] G. Curcio, F. Mocciaro, I. Tarantino et al., "Self-expandable metal stent for closure of a large leak after total gastrectomy," Case Reports in Gastroenterology, vol. 4, no. 2, pp. 293-297, 2010.

[23] L. Cipolletta, M. A. Bianco, G. Rotondano, R. Marmo, R. Piscopo, and C. Meucci, "Endoscopic clipping of perforation following pneumatic dilation of esophagojejunal anastomotic strictures," Endoscopy, vol. 32, no. 9, pp. 720-722, 2000.

[24] M. A. Mauro, R. E. Koehler, and T. H. Baron, "Advances in gastrointestenal intervention: The treatment of gastroduodenal and colorectal obstructions with metallic stents," Radiology, vol. 215, no. 3, pp. 659-669, 2000. 
[25] P. D. Siersema and M. M. C. Hirdes, "What is the optimal duration of stent placement for refractory, benign esophageal strictures?" Nature Clinical Practice Gastroenterology and Hepatology, vol. 6, no. 3, pp. 146-147, 2009.

[26] J. H. Kim, H.-Y. Song, E. K. Choi, K. R. Kim, J. H. Shin, and J.O. Lim, "Temporary metallic stent placement in the treatment of refractory benign esophageal strictures: results and factors associated with outcome in 55 patients," European Radiology, vol. 19, no. 2, pp. 384-390, 2009.

[27] J. H. Kim, J. H. Shin, and H.-Y. Song, "Benign strictures of the Esophagus and Gastric outlet: interventional management," Korean Journal of Radiology, vol. 11, no. 5, pp. 497-506, 2010. 


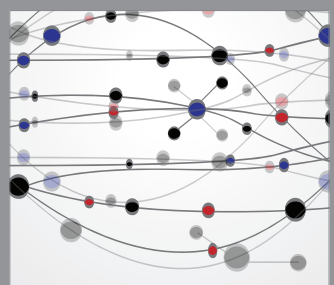

The Scientific World Journal
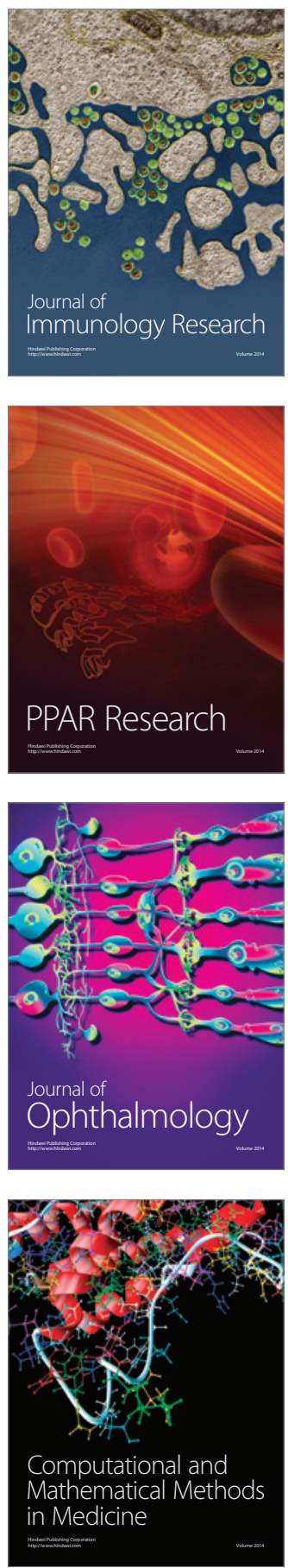

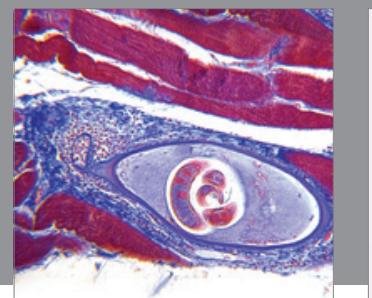

Gastroenterology

Research and Practice
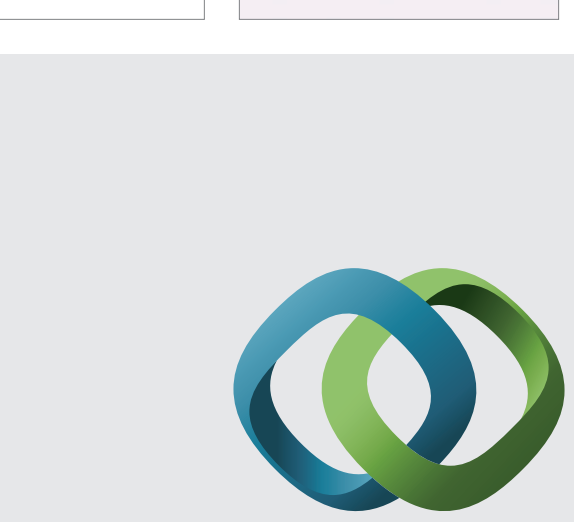

\section{Hindawi}

Submit your manuscripts at

http://www.hindawi.com
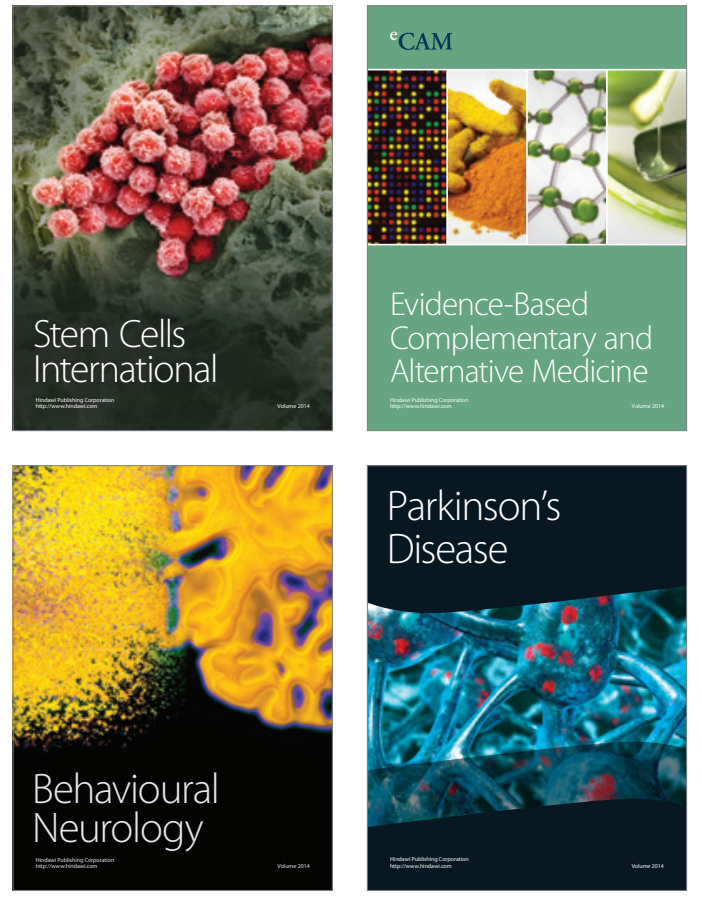
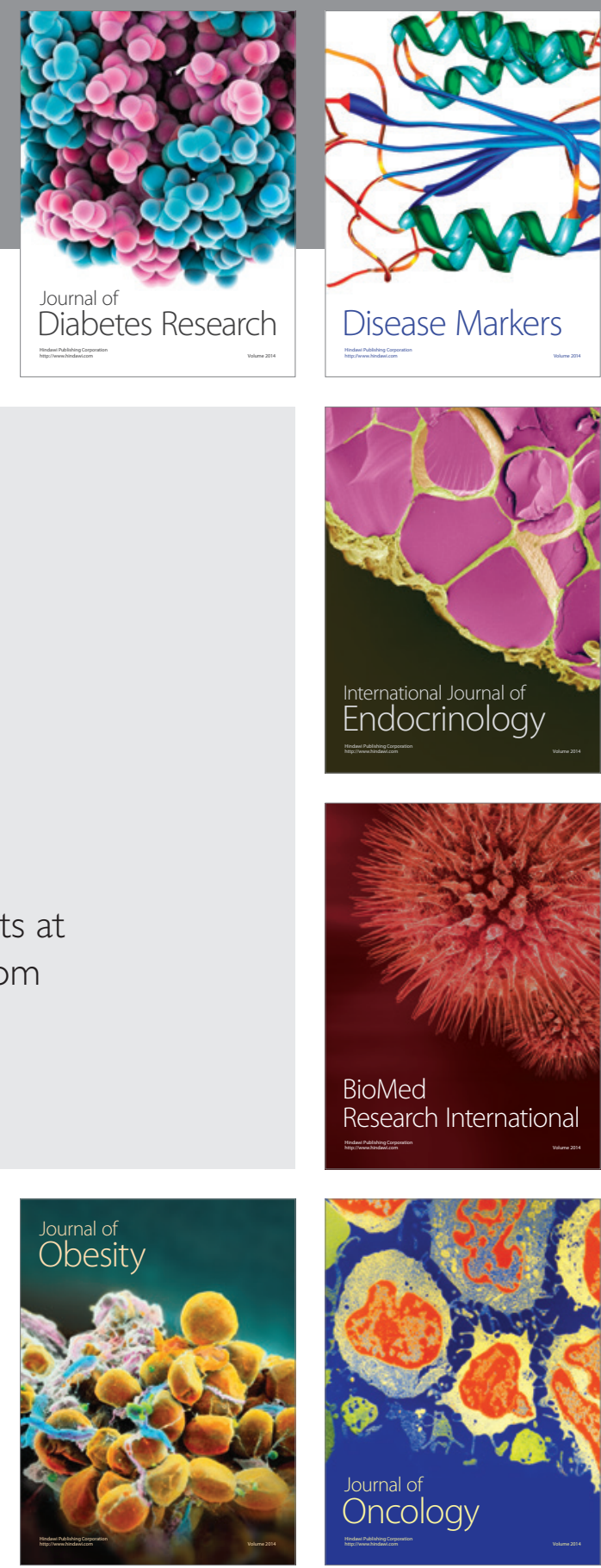

Disease Markers
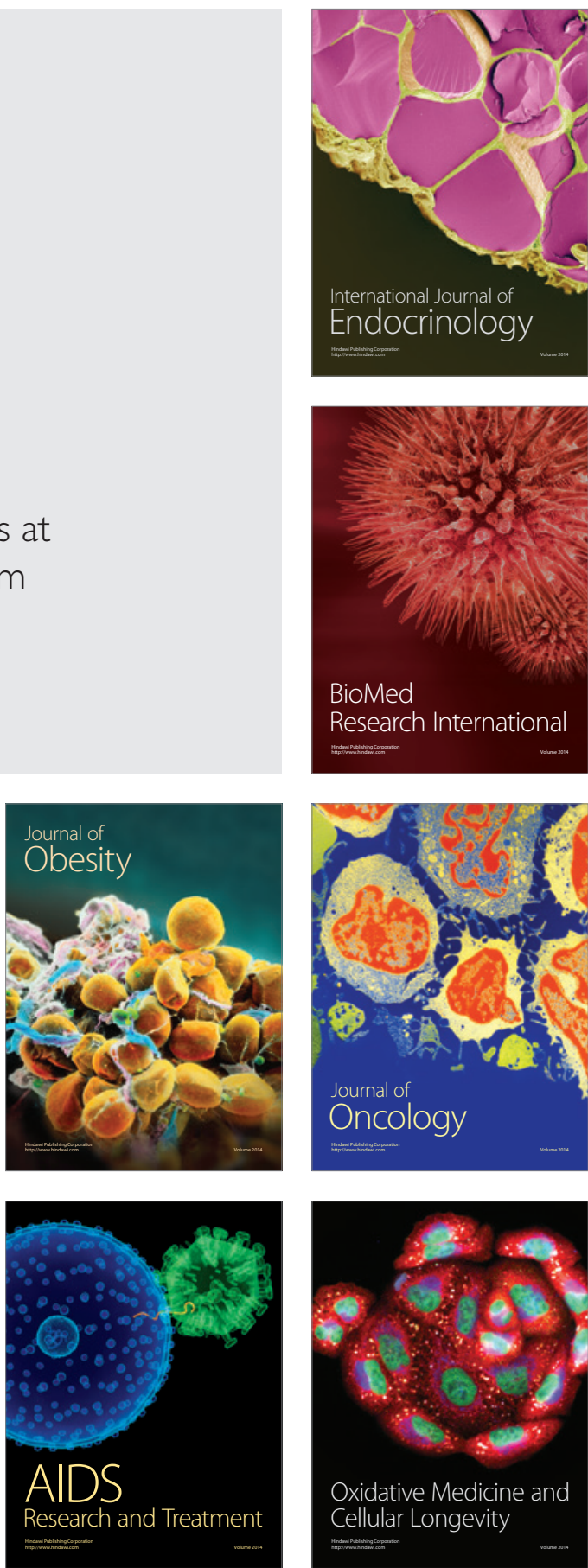